\title{
Diabetic Neovascularization Defects in the Retina Are Improved by Genistein Supplementation in the Ovariectomized Rat
}

\section{Hadi yousefi}

Hamadan University of Medical Sciences

Alireza Komaki

Hamadan University of Medical Sciences

Siamak Shahidi

Hamadan University of Medical Sciences

Parisa Habibi ( $\sim$ Dr.habibi2007@gmail.com )

Hamadan University of Medical Sciences https://orcid.org/0000-0003-3747-6961

\section{Reihaneh Sadeghian}

ShahreKord University Faculty of Natural Resources and Geosciences

Nasser Ahmadiasl

Tabriz University of Medical Sciences

\section{Faeze Daghigh}

Islamic Azad University Khoy

\section{Research Article}

Keywords: Angiogenesis, Genistein, Anti-oxidant, Ovariectomized rats, Inflammatory

Posted Date: May 4th, 2021

DOI: https://doi.org/10.21203/rs.3.rs-485874/v1

License: (a) (1) This work is licensed under a Creative Commons Attribution 4.0 International License. Read Full License 


\section{Abstract}

Genistein seems to have a protective and therapeutic effect on conditions associated with neovascular growth in the retina. This study investigated the angiogenesis, anti-oxidant, and anti-inflammatory effect of genistein on the retinas in ovariectomized diabetic rats. In this study, forty female albino Wistar rats were divided into four groups ( $\mathrm{n}=8$ per group): sham, OVX, OVX +diabetes (OVX.D), and OVX.D +genistein (OVX.D.G). OVX induced by bilateral ovaries removing and then high-fat diet (HFD) and a low dose of streptozotocin (STZ) (1 mg/kg: IP injected) was used for diabetes induction (OVX.D) with eight weeks of genistein treatment (OVX.D.G). At the end of 8 weeks, the retina was removed under anesthesia. The samples were used to measure ERK, MMP-2, VEGF, and Nf-KB by western blotting and inflammatory factors ELISA and oxidative stress. Measurements of GSH and MDA showed that OVX and specially OVX.D significantly decreased GSH and increased MDA level in the retina, but genistein reversed these effects OVX.D.G groups. Also, OVX and OVX.D significantly increased VEGF, MMP-2, p-ERK, Nf-KB, IL-1 $\beta$, and TNF-a expression in the retina of OVX and OVX.D groups in comparison to the sham group $(P<0.05)$. However, a significant reduction of these proteins was observed in the genistein-treated group $(P<0.05)$.It can be concluded ovariectomy and subsequently estrogen deficiency caused the development of inflammation, neovascularization, and then retinopathy in STZ-induced diabetic ovariectomized rats. Based on the results, genistein administration may be the practical approach for improving symptoms and complications of ovariectomized diabetic retinopathy.

\section{Introduction}

Retinal neovascularization is an essential pathologic condition in several ocular diseases, such as proliferative diabetic retinopathy, and leading to the defeat of vision. The abnormal new generated blood vessels can develop into the vitreous of the eye and consequence in retinal detachment (Wang et al., 2005). The oxygen therapy cessation in premature newborns induces relative retinal hypoxia, and then neovascularization in the retina happens in an attempt to overcome retinal hypoxia. The proliferative retinopathy in diabetes is the leading cause of new blindness in a diabetic population (EchouffoTcheugui et al., 2013). Several angiogenic factors, such as vascular endothelial growth factor (VEGF), are associated with the progress of diabetic retinopathy (Noma et al., 2002). VEGF has a prominent role in both standard and abnormal retinal vascular growth (Zhao et al., 2021).

On the other hand, one of the complications in postmenopausal people, especially in its acute and nonphysiological form, is visual impairment. Recent studies emphasize the protective effect of estrogen in maintaining visual health in women, especially in menopause. The presence of estrogen receptors in the retina, lens, cornea, and iris is an actual reason for this claim (Feola et al., 2019, Sengupta et al., 2019).

In recent years, flavonoids derived from natural plants have become a topic of interest. Because they have potent anti-oxidant activity and low toxicity and side effects, which makes them very effective as potential therapeutic agents. Soy isoflavone Genistein seems to have a protective and therapeutic effect on conditions associated with neovascular growth in the retina (Ronghua et al., 2018, Dongare et al., 
2015). It has been shown that soybean genistein can prevent choroid capillary's developing and corneal neovascularization induced by fibroblastic growth factor (Wang et al., 2005). Also, it has been showing that genistein significantly decreased VEGF protein expression induced by hypoxia in cultured rabbit retinal pigment epithelium cells (Wang et al., 2005, Ronghua et al., 2018).

Therefore, according to the effect of genistein in reducing inflammation, oxidative stress, and angiogenesis, and the role of inflammation, stress oxidation, and angiogenesis in visual impairment caused by diabetes and ovariectomy, in this study, we have investigated the effect of genistein on the expression of factors involved in inflammation, stress oxidation and angiogenesis in the retina of diabetic ovariectomized rats.

\section{Material And Methods \\ 2.1. Animal care}

Forty- female Wistar rats (weighing 180-220g, 6-7 weeks old) were purchased from Experimental Animal Research Center, Faculty of Medicine, University of Hamadan, Hamadan, Iran. All rats were preserved under controlled conditions (temperature of $22-24^{\circ} \mathrm{C}$ with $12 / 12$ - hours of the light-dark cycle). Before the experiments, all rats were given at least one week to adjust to their new surroundings. The institutional ethics committee at Hamadan University of Medical Sciences approved the animal care, procedures, and surgery, carried out in compliance with the Care and Use of Laboratory Animals (Code of Ethics Committee: Grant Number: IR.UMSHA.REC.1397.637).

\subsection{Protocol}

Rats were randomized into two groups, including sham and ovariectomized (OVX) groups. OVX was rerandomized into three new groups OVX only, OVX + diabetic (OVX.D), OVX + D + genistein (OVX.D.G) ( $n=8$ per each group). The ovariectomy induction was performed under anesthesia (ketamine $50 \mathrm{mg} / \mathrm{kg} \mathrm{\&}$ xylazine $5 \mathrm{mg} / \mathrm{kg}$ : IP injection). Then the ovaries were bilaterally removed from a small incision of the ventral abdominal midline area, and after ovariectomy, the abdominal wall was sutured finally. After removing ovaries, rats were housed under good conditions to recover. In the sham surgery, animals were anesthetized with ketamine hydrochloride $(50 \mathrm{mg} / \mathrm{kg})$ and xylazine $(5 \mathrm{mg} / \mathrm{kg})$. The ventral abdominal midline wall was opened similarly to the OVX rat. Then the abdominal wall was sutured (Habibi et al., 2016). After surgical recovery, diabetes in animals was induced with high-fat-diet (HFD) ad libitum for four weeks. The HFD component was including protein (\%25), carbohydrate (\%17), and fat (\%58). Then single dose streptozotocin (Sigma, St. Louis, Mo, USA) (30 mg/kg; IP injection), dissolved in $10 \mathrm{mM}$ sodium citrate, $\mathrm{pH} 4.5$, with $0.9 \% \mathrm{NaCl}$, and then injected into diabetic groups at the four weeks ending. In the sham surgery, the group was injected with $0.4 \mathrm{~mL}$ of sodium citrate buffer, $\mathrm{pH} 4.5$. Fasting blood glucose levels were measured with a glucometer after 6 hours of fasting. Rats in the diabetic groups were confirmed as a diabetic model when tail vein blood glucose reached upper than $200 \mathrm{mg} / \mathrm{dl}$ (Habibi et al., 2020). Genistein (Sigma Aldrich, USA) was dissolved in DMSO and subcutaneously injected for eight weeks (1 mg/kg/day) (Habibi et al., 2017), concurrent with the onset of the HFD regime. At the end of 8 
weeks, the retina tissues were removed under anesthesia and used for molecular evaluations. Western blotting protocol and ELISA analysis were performed on retinas tissue homogenates.

\subsection{Western blotting}

The western blotting protocol was performed on homogenates of retinal tissue. In this method, snapfrozen retinal tissue was homogenized in RIPA buffer. This buffer was supplemented with a protease inhibitor cocktail containing leupeptin, pepstatin, chymostatin, aprotinin, and antipain ( $5 \mu \mathrm{g} / \mathrm{ml}$ each). The homogenized tissues rotated for $20 \mathrm{~min}$ and then centrifuged at $12,000 \times \mathrm{g}$ for $10 \mathrm{~min}$ at $4^{\circ} \mathrm{C}$. After centrifuging, the supernatant was collected and stored at $-80^{\circ} \mathrm{C}$. The proteins were detached by SDSPAGE (10 $\mu \mathrm{g}$ supernatant loaded per each well) and then electrophoretically transferred onto PVDF membranes. Nonspecific binding was blocked by 2-hour incubation of the membranes in $5 \%(\mathrm{w} / \mathrm{v})$ nonfat dry milk in Tris-buffered saline ( $\mathrm{pH}$ 7.5). The PVDF membranes were then incubated for 2 hours at room temperature (at $4^{\circ} \mathrm{C}$ ) with primary antibodies (ERK, p-ERK, VEGF, MMP2, and $\beta$-actin: Santa Cruz, USA (1:500); Anti p65 Nf-kB: Abcam, Germany (1:1250)) diluted in the antibody buffer containing 1\% (w/v) nonfat dry milk in TBS-T (0.05\% ( $\mathrm{v} / \mathrm{v})$ Tween-20 in Tris-buffered saline), and washed three times with TBS-T, then incubated for 1 hour with a secondary antibody (Goat anti-Rabbit; Santa Cruz, USA (1:5000)) in the antibody buffer. The PVDF membranes were developed for visualization using enhanced chemiluminescence (ECL) detection kit (Pierce, Rockford, IL). Anti- $\beta$-actin was used as a loading control. Band intensities on The PVDF membranes were quantified by densitometry using the Image $j$ software.

\subsection{Enzyme-linked immunosorbent assay (ELISA)}

Freshly isolated retina tissues were homogenized with PBS and centrifuged at 11,100×g for 20 minutes at four ${ }^{\circ} \mathrm{C}$, and then the supernatants were isolated. The retina extracts were used for ELISA analysis. The levels of IL-1 $\beta$ (Abcam) and TNF-a (Diaclone) were measured using ELISA kits according to the manufacturer's protocol.

\subsection{Stress oxidation}

The accumulation of TBARS (thiobarbituric acid reactive substances) in the retinas homogenates expressed as malondialdehyde (MDA) level was used for lipid peroxidation. MDA ( $\mathrm{nmol} / \mathrm{mg}$ protein) was evaluated at $532 \mathrm{~nm}$ (UV/visible U-200L spectrophotometer, Spectra Max 190, Molecular Devices, USA.

In the present study, GSH Kit (Kiazist, Iran) was used to measure GSH level. The mechanism of this kit is based on the binding of Ellman reagent (DNTB) to the regenerated thiol groups and the formation of a color complex. The level of free thiol groups in each sample was calculated using the standard curve. After dividing by the protein concentration of the sample was reported as $\mathrm{nmol} / \mathrm{mg}$ protein.

\subsection{Statistical analysis}

All data were described as the mean \pm SEM, and differences between all groups were evaluated by oneway analysis of variance (ANOVA) with Tukey's multiple comparison post-test A value of $P<0.05$ was considered statistically significant. 


\section{Results}

\subsection{Effect of genistein on stress oxidation levels in the retina}

At eight weeks after STZ administration and ovariectomized surgery, MDA and glutathione (GSH) levels were measured in the retina. Measurements of MDA (Fig. 1a) and GSH (Fig. 1b) showed that OVX and OVX.D significantly decrease GSH and increase MDA level in the retina, but genistein reversed these effects in OVX.D.G groups (Fig. 1, p<0.05).

\subsection{Effect of genistein on IL-1 $\beta$ and TNF- $\alpha$ level in the retina}

After sampling, the IL-1 $\beta$ and TNF-a proteins level were measured by ELISA. Measurements of IL-1 $\beta$ and TNF-a level (Fig. 2a \& b) with ELISA showed overexpression of these proteins in OVX and specially OVX.D in the compared sham group. However, a significant reduction of IL-1 $\beta$ and TNF-a was observed in genistein treated group (OVX.D.G).

\subsection{Effect of genistein on VEGF, MMP-2, Nf-kB, and p-ERK levels in the retina}

At eight weeks after STZ administration and ovariectomized surgery, VEGF, p-ERK, MMP-2, and Nf-kB proteins level were measured by western blotting. Densitometric measurements of western blotting bounds (Fig. 3a) with image j software showed that OVX and OVX.D cause an increase in VEGF proteins level $(p<0.05)$, but a significant reduction of VEGF was observed in the genistein treated group. Genistein significantly decreased VEGF proteins level in this group (Fig. 3a, $p<0.05$ ). Besides, OVX.D causes an increase in ERK phosphorylation, Nf-kB, MMP2 proteins level compared to the sham (Fig. 3b-d, $p<0.05$ ) genistein significantly decreased ERK phosphorylation, Nf-kB, MMP2 protein level. Genistein in OVX.D.G significantly decreased these proteins compared to the OVX.D group (Fig. 3.b-d, p<0.05).

\section{Discussion}

This study evaluated the effects of genistein on the ERK signaling pathway and neovascularization in retinal tissue of ovariectomized diabetic rats. We showed that the ERK phosphorylation, VEGF, MMP2, and $\mathrm{Nf}-\mathrm{kB}$ proteins level and inflammatory factors were significantly higher in the OVX.D group than in the sham group at four weeks after OVX surgery and STZ administration. Genistein reversed these effects in OVX.D.G groups in comparison to OVX.D groups. Also, glutathione decreased, and MDA increased in OVX.D, but genistein reversed these effects in OVX.D.G groups.

A causal association between diabetic abnormal high glucose level and the progress of retinal vascular dysfunction has been recognized, such that glucose regulation in diabetic patients decreases the development of the disease (Control and Group, 1993). Therefore, hyperglycemia has been associated 
with the activation of more critical signaling pathways, including nitrative and oxidative stress, which contribute to retinal neovascularization and diabetic retinopathies (Huang and Sheibani, 2008). Hypoxia/reoxygenation conditions in diabetes or any pathological conditions are the most important causes of ERK, MMP2, and VEGF expression, which are implicated in several neovascularization (Zhang and Tao, 2017). Molecular studies have been shown that ERK expression is related to vascular endothelial cell proliferation, thereby contributing to angiogenesis. Activated ERK was detected in accelerated neovascularization during wound healing and ischemia (Elsherif et al., 2014). Also, it has been shown that the expression of IL1 $\beta$, ERK, and caspase 3 increases in the lungs of the OVX.D group, which genistein decreased them in lung tissue of ovariectomized diabetic rats (Daghigh et al., 2017). These results indicate the role of ERK in tissue damage. While genistein improves these effects. One of the present study findings was an increase of MMP2 in the OVX and ovariectomized diabetic group, which was decreased by genistein. Similar to this study, it has been shown that MMP proteins decrease in retinal pigment epithelium choroid complex when treated with soy isoflavone genistein after choroidal neovascularization induction (Kinoshita et al., 2014).

In the neovascularization process, angiogenic factors increased endothelial cell's basement membrane degradation, migration, and proliferation, causing new capillary tube formation (Hanahan and Folkman, 1996). The endothelial cell's basement membrane is disrupted by proteolytic enzymes such as MMPs (Vu and Werb, 2000). MMP-2 and MMP-9 play an essential role in the hydrolyzation of endothelial cell's basement membrane components (Kinoshita et al., 2014, Hiraoka et al., 1998). Also, our results showed that the NF-kB expression markedly increased in the ovariectomized diabetic group than in the sham control groups. This shows that MMP-2 was upregulated via the increased activity of the NF-kB. This result is consistent with the previous investigations, which showed that the NF-kB activation is increased proliferation, angiogenesis, and apoptosis in endometriosis(Kunicka et al., 2019, Calibasi-Kocal et al., 2019). It has been shown that NF- $\beta B$ acts via regulation of the MMPs expression in the adhesion and invasion of endometriosis cells on the peritoneal surface (Lee et al., 2010, Gottschal et al., 2002). A previous study has shown that MMP-2 is expressed in the endometrial graft in the peritoneum (Ueda et al., 2002).

Sex hormone estrogen increases transcription factors that modify the activity of chief proinflammatory cytokines (Corcoran et al., 2010). The sex hormone estrogen receptors in the retina suggest that estrogen has many functions in this tissue. Additionally, the estrogen has potent anti-oxidation properties, which may cause neuroprotection without including a receptor-mediated process (Azcoitia et al., 2011).

Oxidative stress and neovascularization lead to diabetic retinopathy, an essential complication of diabetes mellitus (DM) and the leading causes of blindness and visual complication in diabetic populations (Varma et al., 2007). Previous studies have shown that hyperglycemia can increase mitochondrial reactive oxygen species (ROS), stimulates many signaling pathways causing tissue injury (Wu et al., 2014). Retinal ROS increasing stabilizes hypoxia-inducible factor- $1 \alpha$ and causes the upregulation of VEGF and other angiogenic factors (Masuda et al., 2017). 
VEGF is distributed in animal and human organs such as the brain, kidney, liver, eye, and other tissues. Under normal conditions, there is low content of VEGF in the retinal cells (Sant et al., 2018). Under physiological conditions, the low concentration of VEGF in the eyes is essential to preserve the integrity of the ocular blood vessels. However, overexpression of this angiogenic factor in ocular tissue will cause neovascularization (Du et al., 2018). VEGF plays a vital role in the pathogenesis of diabetic retinopathy, which is produced from the retinal ganglion cells, pigment epithelium cells, smooth muscle cells, and Muller cells in the human choroids and retinas, and its expression is regulated mainly by tissue oxygen levels (Ishida et al., 2003). In the present study, we showed VEGF overexpression in the ovariectomized diabetic group.

Similar to our investigation, in the previous studies, it has been shown that VEGF expression increases in the retina of STZ-induced diabetic rats. These results suggest that diabetes induces neovascularization through increasing VEGF expression in the retinas. Our results showed that genistein decreases the VEGF levels in the OVX.D.G group.

On the other hand, estrogen insufficiency by menopause or ovariectomy causes inflammation and stress oxidation by increasing the TNF- $a$ and MDA levels, respectively, which can cause eye complications in these patients (Daghigh et al., 2017). In this study, we showed that oxidative factors increased and antioxidants decreased in OVX.D. However, genistein reversed these effects in OVX.D.G groups; reducing oxidative stress may lead to a decrease in neovascularization in the retina by reducing VEGF and inflammatory factors.

Moreover, blockade of ERK signaling pathway decreases VEGF induced proliferation of endothelial cell in a placental artery (Liao et al., 2009). MMP2 is another factor involved in angiogenesis. The processing of angiogenesis is related to vascular basement membrane degradation, necessary for migration of endothelial cells and proliferation (Song et al., 2015).

VEGF expression is increased by hypoxia and hyperglycemia, two major causes of retinal neovascularization. Besides, VEGF is regulated by ERK signaling cascade (Hashimoto et al., 2006). In the present study, we showed that ERK phosphorylation, VEGF, MMP2, and Nf-kB proteins level were significantly higher in the OVX.D group that it can induce retinal neovascularization and injuries. Nevertheless, genistein reversed these effects in the retina of OVX.D.G.

\section{Conclusion}

In conclusion, estrogen deficiency induced by bilateral ovariectomy caused retinopathy and neovascularization in STZ-induced diabetic rats. Based on the results, genistein may be the practical approach for improving symptoms and complications of ovariectomized diabetic retinopathy.

\section{Declarations}


Acknowledgments: The authors would like to express their gratitude to the Neurophysiology Research Center and Vice-chancellor staff for Research and Technology, Hamadan University of Medical Sciences, for helping them carry out this project.

Funding: This research was supported by a grant (Grant number: 9711096780) from the Hamadan University of Medical Sciences.

Availability of data and materials: The data are available for any scientific use with kind permission.

Ethics approval and consent to participate: All experimental procedures using rats were conducted by the animal care and use guidelines approved by the institutional ethics committee at Hamadan University of Medical Sciences (Code of Ethics Committee: Grant Number: IR.UMSHA.REC.1397.637) and were performed following the National Institutes of Health Guide for Care and Use of Laboratory Animals.

Consent for publication: Not applicable.

Competing interests: The authors declare that they have no competing interests.

\section{References}

1. AZCOITIA, I., AREVALO, M.-A., DE NICOLA, A. F. \& GARCIA-SEGURA, L. M. 2011. Neuroprotective actions of estradiol revisited. Trends in Endocrinology \& Metabolism, 22, 467-473.

2. CALIBASI-KOCAL, G., PAKDEMIRLI, A., BAYRAK, S., OZUPEK, N. M., SEVER, T., BASBINAR, Y., ELLIDOKUZ, H. \& YIGITBASI, T. 2019. Curcumin effects on cell proliferation, angiogenesis and metastasis in colorectal cancer. $J$ buon, 24, 1482-1487.

3. CONTROL, D. \& GROUP, C. T. R. 1993. The effect of intensive treatment of diabetes on the development and progression of long-term complications in insulin-dependent diabetes mellitus. New England journal of medicine, 329, 977-986.

4. CORCORAN, M. P., MEYDANI, M., LICHTENSTEIN, A. H., SCHAEFER, E. J., DILLARD, A. \& LAMON-FAVA, S. 2010. Sex hormone modulation of proinflammatory cytokine and CRP expression in macrophages from older men and postmenopausal women. The Journal of endocrinology, 206, 217.

5. DAGHIGH, F., ALIHEMMATI, A., KARIMI, P., HABIBI, P. \& AHMADIASL, N. 2017. Genistein preserves the lungs of ovariectomized diabetic rats: addition to apoptotic and inflammatory markers in the lung. Iranian journal of basic medical sciences, 20, 1312.

6. DONGARE, S. S., GUPTA, S. K., MATHUR, R., SAXENA, R., SRIVASTAVA, S. \& NAG, T. C. 2015. Genistein ameliorates diabetic retinopathy by suppression of oxidative stress, inflammation and angiogenic markers in streptozotocin induced retinal neovascularization in neonatal rats (nSTZ). Investigative Ophthalmology \& Visual Science, $56,175-175$.

7. DU, W., AN, Y., HE, X., ZHANG, D. \& HE, W. 2018. Protection of kaempferol on oxidative stress-induced retinal pigment epithelial cell damage. Oxidative Medicine and Cellular Longevity, 2018. 
8. ECHOUFFO-TCHEUGUI, J., ALI, M., ROGLIC, G., HAYWARD, R. \& NARAYAN, K. 2013. Screening intervals for diabetic retinopathy and incidence of visual loss: a systematic review. Diabetic medicine, 30, 1272-1292.

9. ELSHERIF, L., OZLER, M., ZAYED, M. A., SHEN, J. H., CHERNOFF, J., FABER, J. E. \& PARISE, L. V. 2014. Potential compensation among group I PAK members in hindlimb ischemia and wound healing. PloS one, 9.

10. FEOLA, A. J., FU, J., ALLEN, R., YANG, V., CAMPBELL, I. C., OTTENSMEYER, A., ETHIER, C. R. \& PARDUE, M. 2019. Menopause exacerbates visual dysfunction in experimental glaucoma. Experimental eye research, 107706.

11. GOTTSCHAL, C., MALBERG, K., ARNDT, M., SCHMITT, J., ROESSNER, A., SCHULTZE, D., KLEINSTEIN, J. \& ANSORGE, S. 2002. Matrix metalloproteinases and TACE play a role in the pathogenesis of endometriosis. Cellular Peptidases in Immune Functions and Diseases 2. Springer.

12. HABIBI, P., ALIHEMMATI, A., AHMADIASL, N., FATEH, A. \& ANVARI, E. 2020. Exercise training attenuates diabetes-induced cardiac injury through increasing miR-133a and improving proapoptosis/anti-apoptosis balance in ovariectomized rats. Iranian journal of basic medical sciences, 23, 79-85.

13. HABIBI, P., ALIHEMMATI, A., NOURAZAR, A., YOUSEFI, H., MORTAZAVI, S. \& AHMADIASL, N. 2016. Expression of the Mir-133 and Bcl-2 could be affected by swimming training in the heart of ovariectomized rats. Iranian journal of basic medical sciences, 19, 381.

14. HABIBI, P., BABRI, S., AHMADIASL, N. \& YOUSEFI, H. 2017. Effects of genistein and swimming exercise on spatial memory and expression of microRNA 132, BDNF, and IGF-1 genes in the hippocampus of ovariectomized rats. Iranian journal of basic medical sciences, 20, 856.

15. HANAHAN, D. \& FOLKMAN, J. 1996. Patterns and emerging mechanisms of the angiogenic switch during tumorigenesis. cell, 86, 353-364.

16. HASHIMOTO, T., ZHANG, X.-M., CHEN, B. Y.-K. \& YANG, X.-J. 2006. VEGF activates divergent intracellular signaling components to regulate retinal progenitor cell proliferation and neuronal differentiation. Development, 133, 2201-2210.

17. HIRAOKA, N., ALLEN, E., APEL, I. J., GYETKO, M. R. \& WEISS, S. J. 1998. Matrix metalloproteinases regulate neovascularization by acting as pericellular fibrinolysins. cell, 95, 365-377.

18. HUANG, Q. \& SHEIBANI, N. 2008. High glucose promotes retinal endothelial cell migration through activation of Src, PI3K/Akt1/eNOS, and ERKs. American Journal of Physiology-Cell Physiology, 295, C1647-C1657.

19. ISHIDA, S., USUI, T., YAMASHIRO, K., KAJI, Y., AHMED, E., CARRASQUILLO, K. G., AMANO, S., HIDA, T., OGUCHI, Y. \& ADAMIS, A. P. 2003. VEGF164 is proinflammatory in the diabetic retina. Investigative ophthalmology \& visual science, 44, 2155-2162.

20. KINOSHITA, S., NODA, K., TAGAWA, Y., INAFUKU, S., DONG, Y., FUKUHARA, J., DONG, Z., ANDO, R., KANDA, A. \& ISHIDA, S. 2014. Genistein attenuates choroidal neovascularization. The Journal of nutritional biochemistry, 25, 1177-1182. 
21. KUNICKA, Z., KURZYNSKA, A., SZYDLOWSKA, A., MIERZEJEWSKI, K. \& BOGACKA, I. 2019.

Peroxisome proliferator-activated receptor gamma ligands affect NF-kB and cytokine synthesis in the porcine endometrium-An in vitro study. American Journal of Reproductive Immunology, 81, e13053.

22. LEE, E. J., KIM, W. J. \& MOON, S. K. 2010. Cordycepin suppresses TNF-alpha-induced invasion, migration and matrix metalloproteinase-9 expression in human bladder cancer cells. Phytotherapy Research, 24, 1755-1761.

23. LIAO, W.-X., FENG, L., ZHANG, H., ZHENG, J., MOORE, T. R. \& CHEN, D.-B. 2009. Compartmentalizing VEGF-induced ERK2/1 signaling in placental artery endothelial cell caveolae: a paradoxical role of caveolin-1 in placental angiogenesis in vitro. Molecular Endocrinology, 23, 1428-1444.

24. MASUDA, T., SHIMAZAWA, M. \& HARA, H. 2017. Retinal diseases associated with oxidative stress and the effects of a free radical scavenger (Edaravone). Oxidative medicine and cellular longevity, 2017.

25. NOMA, H., FUNATSU, H., YAMASHITA, H., KITANO, S., MISHIMA, H. K. \& HORI, S. 2002. Regulation of angiogenesis in diabetic retinopathy: possible balance between vascular endothelial growth factor and endostatin. Archives of ophthalmology, 120, 1075-1080.

26. RONGHUA, H., ZHOU, G., KONG, L. \& CHENYU, L. 2018. Inhibitory effects of Genistein on hyperoxiainduced retinal neovascularization. Chinese Journal of Experimental Ophthalmology, 36, 29-33.

27. SANT, D. W., CAMARENA, V., MUSTAFI, S., LI, Y., WILKES, Z., VAN BOOVEN, D., WEN, R. \& WANG, G. 2018. Ascorbate suppresses VEGF expression in retinal pigment epithelial cells. Investigative ophthalmology \& visual science, 59,3608-3618.

28. SENGUPTA, D. C., LANTZ, C. L., RUMI, M. K. \& QUINLAN, E. M. 2019. 17a Estradiol promotes plasticity of spared inputs in the adult amblyopic visual cortex. Scientific Reports, 9, 1-14.

29. SONG, H., PAN, D., SUN, W., GU, C., ZHANG, Y., ZHAO, P., QI, Z. \& ZHAO, S. 2015. SiRNA directed against annexin II receptor inhibits angiogenesis via suppressing MMP2 and MMP9 expression. Cellular Physiology and Biochemistry, 35, 875-884.

30. UEDA, M., YAMASHITA, Y., TAKEHARA, M., TERAI, Y., KUMAGAI, K., UEKI, K., KANDA, K., HUNG, Y.-C. \& UEKI, M. 2002. Gene expression of adhesion molecules and matrix metalloproteinases in endometriosis. Gynecological endocrinology, 16, 391-402.

31. VARMA, R., MACIAS, G. L., TORRES, M., KLEIN, R., PEÑA, F. Y., AZEN, S. P. \& GROUP, L. A. L. E. S. 2007. Biologic risk factors associated with diabetic retinopathy: the Los Angeles Latino Eye Study. Ophthalmology, 114, 1332-1340.

32. VU, T. H. \& WERB, Z. 2000. Matrix metalloproteinases: effectors of development and normal physiology. Genes \& development, 14, 2123-2133.

33. WANG, B., ZOU, Y., LI, H., YAN, H., PAN, J.-S. \& YUAN, Z.-L. 2005. Genistein inhibited retinal neovascularization and expression of vascular endothelial growth factor and hypoxia inducible factor $1 \mathrm{a}$ in a mouse model of oxygen-induced retinopathy. Journal of Ocular Pharmacology \& Therapeutics, 21, 107-113. 
34. WU, Y., TANG, L. \& CHEN, B. 2014. Oxidative stress: implications for the development of diabetic retinopathy and antioxidant therapeutic perspectives. Oxidative medicine and cellular longevity, 2014.

35. ZHANG, L. \& TAO, L. 2017. miR-132 promotes retinal neovascularization under anoxia and reoxygenation conditions through up-regulating Egr1, ERK2, MMP2, VEGFA and VEGFC expression. Int J Clin Exp Pathol, 10, 8845-8857.

36. ZHAO, X., GAO, M., LIANG, J., CHEN, Y., WANG, Y., WANG, Y., XIAO, Y., ZHAO, Z., WAN, X. \& JIANG, M. 2021. SLC7A11 Reduces Laser-Induced Choroidal Neovascularization by Inhibiting RPE Ferroptosis and VEGF Production. Frontiers in Cell and Developmental Biology, 9, 256.

\section{Figures}



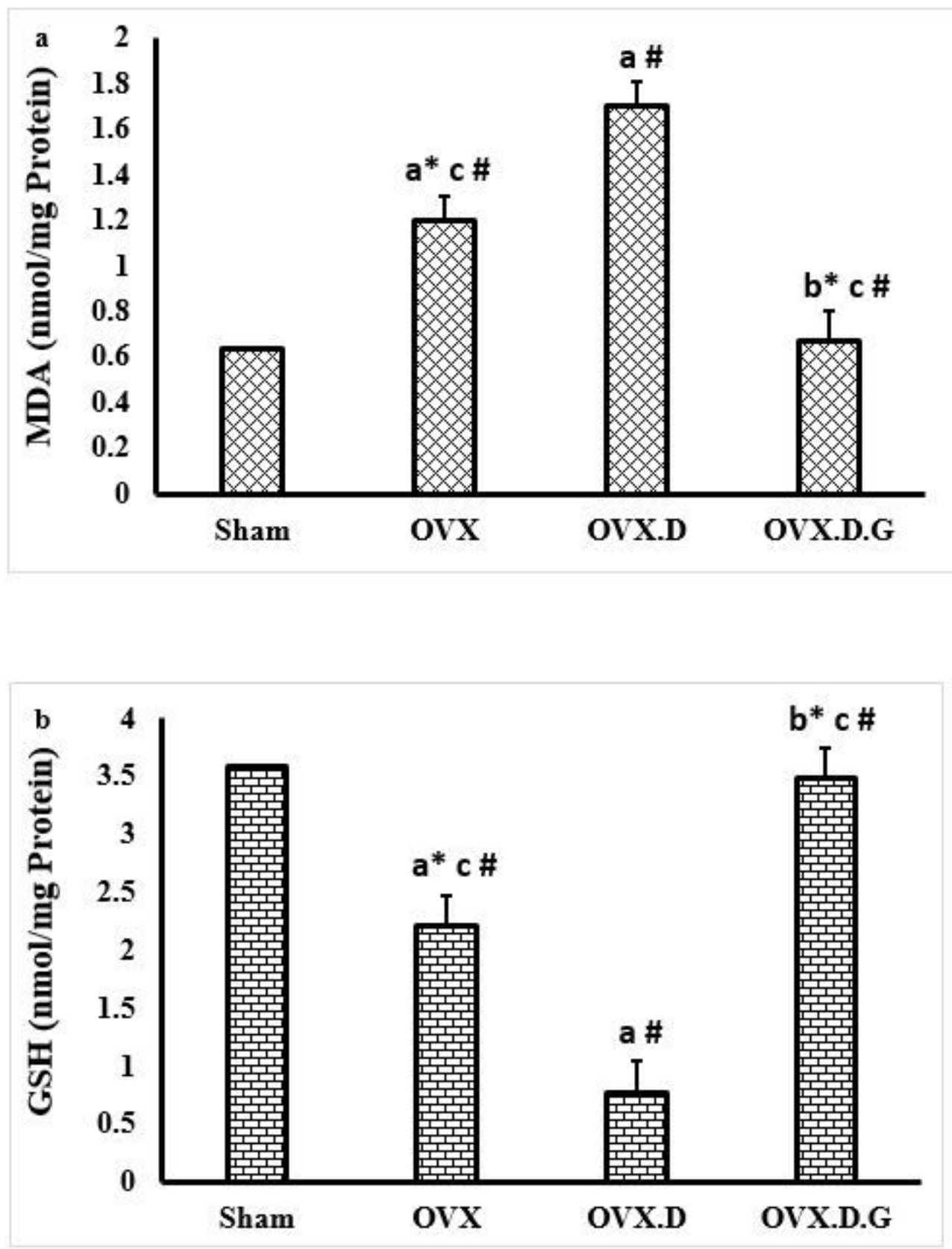

Figure 1

(a) Malondialdehyde (MDA) (b) Glutathione (GSH) concentration in rat retinas homogenates was determined. ${ }^{\star} p \leq 0.05,{ }^{\star \star} p<0.01$ and $\# p<0.001$. a vs sham, b vs OVX, c vs OVX.D. 

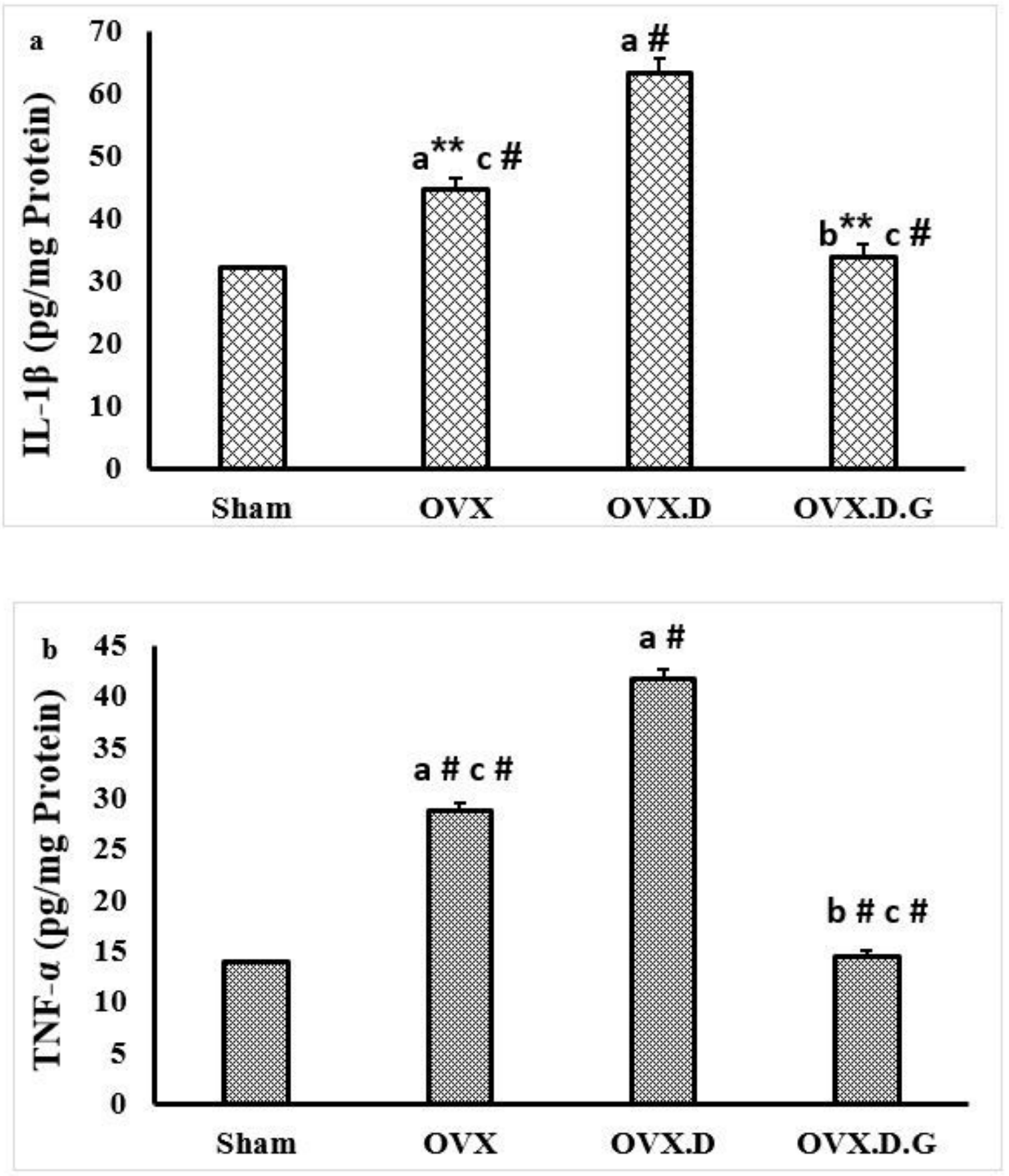

Figure 2

(a) IL-1 $\beta$ (b) TNF-a levels in homogenate retinas was determined by ELISA. ${ }^{*} p<0.01$ and $\# p<0.001$. a vs sham, b vs OVX, c vs OVX.D. 


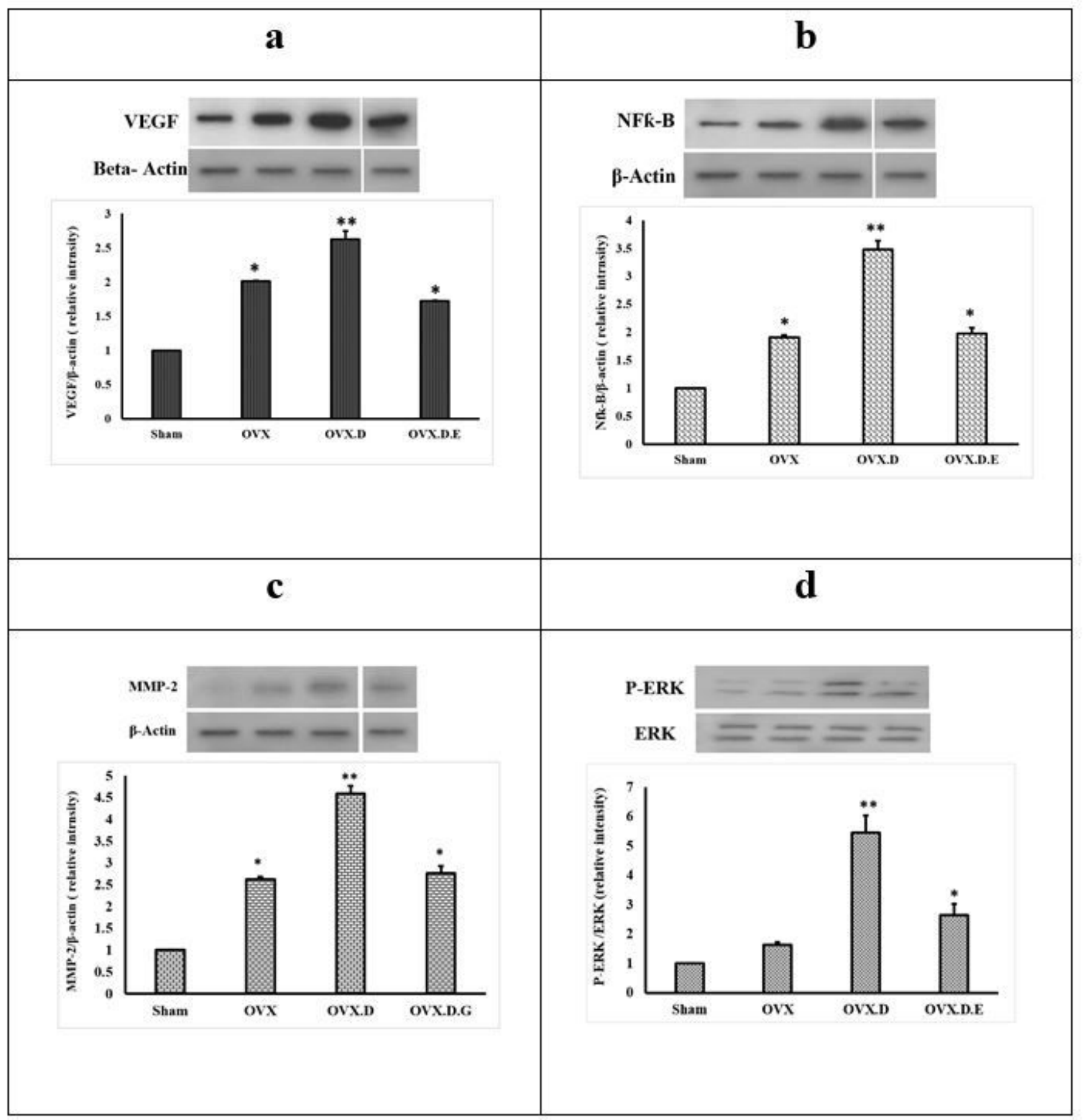

Figure 3

Densitometric measurements of immunoblotting for (a)VEGF, (b)Nf-kB and (c) MMP-2 relative to betaactin, and (d)p-ERK relative to total ERK in different groups of retinas tissue (Fig 1a-d) with image $\mathrm{j}$ software. ${ }^{*} p \leq 0.05$ vs sham, ${ }^{* *} p<0.01$ vs sham, OVX \& OVX.D.E,$\# p<0.05$ vs OVX \& OVX.D. 